\title{
Poesia Política e relações anglo-fracesas no século XIII
}

José Roberto de Almeida Mello

Departamento de História - FFLCH/USP

Para o bom entendimento das razões que levaram os soberanos da França e da Inglaterra a se engalfinhar no longo conflito conhecido como a Guerra dos Cem Anos o século XIII é fundamental. Nele se situaram os dois eventos que formam o pano de fundo para todo o processo belicoso do período subsequente. O primeiro foi a perda de quase toda a porção continental do Império Angevino, ocorrida entre 1202 e 1204, no reinado de João sem Terra. O segundo, o tratado de París de 1259, reconhecendo a posse de Henrique III da Inglaterra sobre a parte restante, agora definitivamente caracterizada como feudo do rei da França, mediante a prestação de homenagem lígia.

Esse tratado permaneceu pois como divisor de água nas relações entre os dois reinos no final da Idade Média. De um lado ele sepultava as aspirações, até então sustentadas por Henrique III, de reaver as terras perdidas por seu pai ou, quando muito, manter a soberania naquelas que conservara (a Gasconha, a ilha de Oléron e outras no canal da Mancha), razão das diversas lutas travadas contra Luís VIII e Luís IX. De outro, ele dava início a um relacionamento jurídico entre senhor e vassalo, que a evolução das idéias políticas e a sucessão dos eventos locais na Gasconlıa e alhures no final do século XIII mostrariam difícil de manter sem sobre* saltos.

Mas, além dessa questão fundamental, o tratado de París e, melhor dizendo, os meados do século XIII constituiram um momento significativo também na apreciação das lutas continentais pela população inglesa que, em princípio, nada tinha a ver com as ambições de seus monarcas naquelas áreas. A aristocracia, em geral possuidora de feudos em ambas as margens do canal, fora obrigada a uma escolha já nos tempos do rei João, e os nobres que apostaram seu futuro na parte insular se desinteressaram daí por 
diante dos domínios continentais. Além do mais, as empreitadas militares de João e Henrique III saiam extremamente onerosas para todos: daí a sistemática recusa dos barões em prestar o auxílio feudal no continente e da comunidade do reino em custear as guerras. A precaução contra tais demandas extras deve ter sido um dos motivos da definição na Magna Carta (item 12,14-16) das ocasiões em que o auxílio feudal e o escudágio poderiam ser requeridos pelo rei.

Essa atitude, revelada nas crônicas, petições e documentos diversos concernentes às relações entre o rei e a comunidade do reino, se manifesta de forma igualmente inequívoca no terreno literário. A Inglaterra começou a produzir no século XIII um tipo de poeșia que se tornou como um espelho da sua evolução política e social no final da Idade Média. Compostas quer em latim, anglo normando, inglês, ou ainda em versos macarrônicos (combinando duas uo três línguas) tais obras têm um caráter bastante variado quanto à forma, extensão e conteúdo, indo do curto dístico sobre qualquer evento até o longo tratado com tema histórico, moral ou político. Portanto as tentativas de editores e estudiosos para enquadrá-las sob um rótulo único não foram até hoje muito felizes e a conhecida expressão "canções políticas" (political songs), embora cômoda, peca por ser muito restritiva.

Dificuldades semelhantes despontam quando tentamos identificar a sua procedência social e a audiência a que se destinavam, pois ao lado de longos poemas em latim - certamente confinados nos limites das comunidades eclesiásticas - aparecem refrões populares em inglês, acompanhados de notação musical, cantadas, sem dúvida pelo populacho ou por vates populares. Portanto é preciso ter sempre em mente tais variações para não se tomar muito ao pé da letra os designativos de "populares" ou de representantes da "opinião pública" a eles aplicados. Na falta da imprensa e de outros meios de comunicação de massa esse gênero literário pode realmente no seu conjunto, e apenas no conjunto, ser encarado como representativo das opiniões da comunidade do reino.

Conquanto tais especimens literários tenham surgido no século XIII, eles se tornariam mais abundantes no período seguinte, como que acompanhando a crescente animaçâo da vida política e social do reino a partir da insularização dos Plantagenetas. Isso é facilmente perceptível na simples enumeração das coletâneas de poemas até hoje publicadas: a grande maioria dos exemplares provém dos séculos XIV e XV, salvo na compilação de Thomas Wright, The Political Songs of England, dedicada inteiramente ao século XIII (1).

(1) - Algumas das principais coletâneas são: as duas de Thomas Wright, The Political Sonqs of England, (Camden Society, Londres: 1839) e The Political 
Tentando cobrir todos os aspectos da evolução histórica da Inglaterra nesses cem anos, Wright parece não ter descoberto na produção insular até meados dos mesmos nada que se referisse às lutas continentais de João e Henrique III, necessitando recorrer aos trovadores gascões e provençais para ilustrá-las. Somente a partir do reino de Eduardo I começaram tais referências a frequentar a poesia da Inglaterra com assiduidade crescente até o início da Guerra dos Cem Anos. A razão desse súbito interesse dos poetas ingleses pela questão francesa e da geral animosidade contra um inimigo há pouco tratado com indiferença ou simplesmente ignorado é um dos pontos, entre outros, que esperamos esclarecer analisando a temá. tica dessa poesia política.

Portanto, para a primeira metade do século XIII tudo o que possuimos em termos literários acerca da política continental dos Plantagenetas são as canções trovadorescas. Apesar de compostas fora da Inglaterra, não representando pois a opinião de seus habitantes, elas constituem um testemunho precioso do gradual distanciamento dos monarcas ingleses das suas possessões francesas, motivado quer por desinteresse, inépcia, ou real impossibilidade de controlar a situação política no pouco que sobrou do velho Império Angevino ao sul do Loire.

O interesse e a participação dos trovadores meridionais nas campanhas militares dos Angevinos não era novo, datando mesmo da época do casamento de Henrique Plantageneta com Leonor da Aquitânia e de sua coroa-

ção como rei da Inglaterra em 1154 (2). Um deles, Bertrand de Born, senhor de Hautefort, celebrizout-se como o intrigante da família Plantageneta, instigador das famosas discórdias entre Henrique II e seus filhos, ganhando por isso u'a menção, algo exagerada, na Divina Comédia.

E, de fato, o tratamento desse material político pelos trovadores nunca ultrapassou o nível da intriga, no sentido mais amplo da palavra. São os episódios locais, a bravura deste ou aquele senhor, o interesse ou o desin-

Poems and Songs relatinq to English History, (Lodres: Longman/Green, 1859-1861, 2 vols.) J. Kail,Twenty-six political and other poems from the Oxford Mss. Digby 102 and Douce 222, (Londres: Kegan Paul, 1904); R. H. Robbins, Historical poems of the XIVth and XVth centuries, (Nova Iorque: Columbia U. P., 1959); F. J. Furnival, Political, Religious and Love Poems, (Londres: Oxford U. P., reimpr. de 1965); I. S. T. Aspin, Anglo-Norman Political Sonqs, (Oxford: Brasil Blackwell, 1953).

(2) - Cf. H. J. Chaytor, The Troubadours and Enqland (Cambridge U. P., 1923). especialmente o segundo capítulo: "The Troubadours and English Politics", pp. 34-97. 
teresse deste ou daquele soberano em socorro seus homens, a covardia, a prodigalidade, a avareza, em suma, as minúcias da política regional e local ou alguns traços do caráter de algum nobre, os focos de atenção desses poetas.

João sem Terra, ao contrário dos irmãos mais velhos (Henrique-o Jovem Rei e Ricardo Coração-de-Leão), nunca teve boa imagem junto aos trovadores que the censuravam o ânimo timorato e a tardança em socorrer seus domínios. Uma canção composta na época da incursão de Filipe Augusto no Poitou, por volta de 1206, lamenta a ameaça que pesava sobre a fortaleza de Thours, exortando os senhores das vizinhanças, entre eles Savari de Mauléon, a defendê-la. Além disso aconselha-os a buscar ajuda junto ao rei da Alemanha, pois não eram amados nem pelo monarca francês nem pelo inglês, e acusa este de haver trocado a região de Bordéus (o Bordelois) por uma mula da Espanha, aludindo ao assédio daquela cidade por Afonso VIII de Castela, que reclamava a Gasconha em nome de sua esposa Leonor, irmã de João sem Terra (3).

Bertrand de Born, filho, num sirventés de 1205, dirigido a Savari de Mauléon, reportando-se aos ataques do soberano francês no Poitou e na Touraine, censura asperamente João por dedicar-se à pescaria, à caçada e ao repouso, enquanto os feudos lilhe eram tirados. Compara-o desfavoravelmente com Ricardo, que nunca hesitou em gastar bastante com a defesa de seu patrimônio. Até Luís o Piedoso - caracterizado habitualmente como um homem fraco e indeciso nas canções do ciclo de Guilherme de Orange - tem mais cotação junto ao trovador por ter sabido socorrer seu vassalo Guilherme, quando assediado pelos sarracenos. As linhas finais apelam a Savari para que não perca mais tempo com tão mau senhor:

\footnotetext{
"Savarics, reis cui cors sofraing

Greu fara bon envasimen,

E pois a flac cor recrezen,

Jamais nuls hom en el non poing." (4)

(Savari, um rei sem coragem dificilmente fará uma incursão com êxito, e já que tem um coração mole e covarde não pode merecer a confiança de ninguém.)
}

(3) - Wright, The Political Songs of England, pp. 1-3.

(4) - id. ibid., p. 6. 
Aliás, Savari de Mauléon constitui um exemplo do que acima dissemos acerca do envolvimento dos trovadores com a política dos Angevinos. Capturado por João durante o sítio do castelo de Mirebeau em 1202, ele foi logo libertado e tornou-se um zeloso partidário seu, fazendo carreira como senescal da Gasconha em 1205, do Poitou em 1211, passando depois para a Inglaterra, onde tomou parte na luta contra os barões revoltosos em 1216. João, aos insucessos continentais, somara também a reprovação dos súditos na ilha, provocando a ira da Igreja e a oposição dos barões, sobretudo dos poderosos senhores setentrionais.

Com Henrique III as cousas não melhoraram no continente, malgrado suas tentativas para recuperar os territórios perdidos. As hesitações e a falta de seriedade de seus projetos começaram a ser sentidos pelos trovadores que desde os anos iniciais do reinado the não pouparam críticas. Amoros dau Luc, pouco antes da queda de La Rochelle em 1224, o exortava a envidar esforços para mantê-la:

\footnotetext{
"Ai rei Engles! Non saiz flac ni vans,

Qe ges aissi la Rochele n'er prisa." '(5)

("Ó rei inglês, não seja fraco nem fútil, para que La Rochelle nunca seja tomada.")
}

Em 1242, inspirado pelo conde de Tolosa, Raimundo XII, ocorreu um grande levante em todo o sul da França, que buscava recuperar sua independência, aniquilada pela investida dos Capetíngios contra os albigenses alguns anos antes. Henrique III foi induzido a participar dele por sua mãe, Isabel de Angoulême, casada com o conde Hugo de la Marche, então em aberta insurreição contra Luís IX. Vários trovadores se pronunciaram sobre esses eventos, lamentando sempre a falta de coragem, ou de iniciativa, do monarca inglês, que emparalhavam na época com Jaime I do Aragão, outro rei prejudicado em seus interesses com a investida de Luís IX na região (6). Um sirventés de Bernard de Rovenac é particularmente duro com Henrique:

"Rey Engles prec que entenda,

Quar fa dechazar

Son pauc pretz per trop temer,

(5) - Citado por Chaytor, op. cit., p. 78 .

(6) - Cf. Chaytor, op. cit., pp. 79-84. 
Quar no'l play qu'els sieus defenda, Qu'aus es tan flacx e marritz

Que par sia adurmitz,

Qu'el rey frances li tolh en plas perdos

Tors et Angieus e Normans e Bretos." (7)

("Rei inglês peço-the que me ouça, pois perde sua pequena glória por demasiado temor, já que não deseja defender os seus homens; assim é tão covarde e vil que parece dormir enquanto o rei francês the toma impunemente Tours e Angiers, Normandos e Bretões.”)

N'outro, de 1254 ele é irônico em relação à atitude cortês de Henrique e Jaime, evitando atacar os domínios de Luís, então ausente na cruzada, o que, aliás, fora enfaticamente proibido pelo papa, com quem Henrique tinha bons motivos para não se atritar no momento (8). Ignorando tais injunções Bernard de Rovenac diz que os dois reis por gentileza resolveram deixar em paz o homem que lhes havia tomado as terras, enquanto conquistava a Síria. Detus certamente saberia recompensá-los por isso. Só que a seu ver tal trégua não passava de u’a má guerra, podendo ser melhor chamada de uma brincadeira, acrescenta ele num trocadilho entre os termos patz e pages.

O tratado de Paris de 1259 trouxe, após esses anos todos de incertezas, novas bases para um acordo entre o soberano francês e seu real vassalo inglês. Daí por diante, em troca da renúncia definitiva à Normandia e ao Anjou, Luís IX reconhecia a Henrique III a posse da Gasconha - com a condição deste se tornar efetivamente seu vassalo - e os direitos feudais sobre um extenso território ao redor das dioceses de Limoges, Cahors e Périgueux, além de um complicado arranjo quanto ao futuro da Saintonge, do Agenais e de terras no Quercy. O tratado, como já dissemos, se rematou por um lado a velha pendenga dos tempos de Ricardo e João, por outro, veio a criar novas fontes de atrito com a interpretação de algumas de suas cláusulas e o descumprimento de outras.

(7) - Wright, The Political Songs of England, p. 37.

(8) - Henrique havia, por mais de uma vez, prometido participar da cruzada, sendo autorizado pelo papa a cobrar dos súditos uma taxa para o custeio da expedição; mas nunca partiu para Jerusalém. Com a morte de Frederico II de Hohenstaufen e a usurpação do trono da Sicília por seu filho bastardo, Manfredo, excomungado pela Santa Sé, aceitou então a oferta da coroa desse reino para seu filho Edmundo, feita por Inocncio IV, transferindo para a campanha contra o usurpador o seu voto e os fundos que arrecadara para a cruzada. O sirventés é publicado por Wright, op. cit., pp. 39-41. 
Como que rematando também esses sessenta anos de lutas inglórias para os Plantagenetas, um poema sobre a "paz com os ingleses", composto por volta de $1264 \mathrm{em}$ meio ao movimento baronial contra Henrique III na Inglaterra e à mediação de Luís IX, satiriza num francês rude o fracasso dớs ingleses e a paz com os franceses. O sarcasmo do autor é voltado para as esperanças (então mortas) e as bazófias dos magnatas insulares em relação à reconquista da Normandia. Mofando da crença dos ingleses nas profecias de Merlim, diz o poeta que este havia predito a conquista de todas as possessões continentais por Filipe Augusto, mas ele, pessoalmente, acreditava que os ingleses ainda as recuperariam. Descreve uma grande assembléia dos nobres em Londres, a qual, (numa alusão às discórdias no reino) houvessem todos eles comparecido, teria certamente produzido resultados desastrosos para o rei da França. Questionados por Henrique sobre a maneira de reaver a Normandia, alguns dos barões dão, com seriedade, respostas hilariantes e ele promete despejar seus exércitos no continente para conquistar París, fazer coroar seu filho Eduardo em S. Dinis e ainda transportar numa carroça a Santa Capela para Londres. A seguinte estrofe ilustra bem o tom jocoso dos absurdos a que o rei inglês se propõe:

"Je pandra bien Paris, je suis toute certaine;

Je bouterra le fu en cele eve qui (fu) Saine;

La moulins arderra; ce fi chos mult gravaine

Se n'i menja de pain de troute la semaine."

("Estou bem certo de que tomarei Paris; incendiarei aquele rio chamado Sena; o moinho queimará; o que será uma cousa muito danosa, se não comerem pão por toda uma semana.")

No final do século XIII, a evolução das relações internacionais ao norte da Europa deu ensejo a novas complicações com os franceses e, desta feita, os ingleses começaram a manifestar gradualmente sua opinião a respeito delas. Como que confirmando, entretanto, sua atitude anterior em relação ao conflito, não foram as intrincadas batalhas judiciais, locais ou no parlamento de Paris, oriundas em parte dos termos do tratado de 1259, que atrairam a atenção dos súditos insulares, mas sim três fatores recentes, preconizadores dos futuros focos de discórdia da Guerra dos Cem Anos, a saber: a ameaça à ilha, o envolvimento de Eduardo I como política flumenga e as guerras com a Escócia.

$\mathrm{O}$ primeiro, a ameaça dos franceses à Inglaterra, consubstanciada quer nos ataques de corsários aos navios de comerciantes ingleses, ou aliados, e a pontos do litoral meridional, quer nos grandiosos projetos de invasão nunca executados (mesmo durante a Guerra dos Cem Anos), em sí não era muito recente, pois a pirataria no Canal sempre existiu e até uma

(9) - Wright, op. cit., p. 67. 
incursão dos franceses na ilha já ocorrera em 1216-17, sob o comando de Luís, filho de Filipe Augusto (10). Este evento forma o episódio central de um poema latino composto certamente em 1217, intitulado por Thomas Wright, The Taking of Lincoln (11): Nele o poeta, embora condenando os desmandos de João e vendo na sua morte obra da Divina Providência, defende ardosamente a causa do herdeiro, o pequeno Henrique (então com nove anos de idade), contra o príncipe estrangeiro, chamado à ilha pelos barrões revoltosos. Ele era para o autor um intruso, uma ameaça ao jovem rei e a todo o reino; além do mais, a luta contra ele assumia foros de cruzada, pois Henrique se achava sob a proteção da Igreja:
"Unio sacra novum maturat ad ardua regem;
Utilitas, pietasque, fides, concurrere fatis
Conjurant, cunctos (que) crucis signare sigillo;
Constiterant vexilla crucis, regemque novellum
Ambierant, bajulosque crucis crux alba decorans
Instabiles statuit fidei fundamine turmas." (12)
("A sacrossanta união amadurece o novo rei para as dificuldades; utili- dade, piedade e fé prometem conjuntamente concorrer com os fados e marcá-los todos com o selo da Cruz; elas haviam levantado o estan- darte da Cruz e se reunido em torno do novo rei, enquanto a alva Cruz decorando os seus portadores fixava as instáveis tropas nos fundamentos da fé.")

No entanto, nessa obra, a invasão da Inglaterra só é considerada em relação à possível evicção do jovem rei em proveito do usurpador estrangeiro. Em nenhum momento o autor menciona a questão continental. Somente no reinado de Eduardo I, a poesia política insular começou a tomar conhecimento dela e o curioso é que justamente o primeiro poema a tratar do assunto relembra aos ouvintes, ou leitores, o fracasso da tentativa de $1216-17$.

Em outubro de 1295 foi executado em Londres como traidor um certo Tomás Turberville, acusado de espionagem em favor do rei da França. O caso ficou famoso na época, sendo noticiado por diversos cronistas (13). O réu participara de uma expedição inglesa à Gasconha em 1294,

(10) - Sobre o evento consultar F. M. Powicke, The Thirteenth Century, (The Oxford History of England, Oxford: Clarendon Press, 1953), pp. 8-15.

(11) - The Political Songs of England, pp. 19-27.

(12) - IbidL, pp. 22-23.

(13) - Cf. J. G. Edwards, "The Treason of Thomas Turberville" in Studies in Medieval History, presented to F. M. Powicke, ed. por R. W. Hunt, W. A. Pantin e R. W. Southern (Oxford, The Clarendon Press, reimpr. de $1969-1$ a ed. 1948), pp. 296-309. 
durante a qual foi capturado pelo adversário e, após algum tempo, libertado para agir como espião junto à corte na Inglaterra. Sua prisão e execução vêm narradas num curto poema anglo-normando, escrito entre o final de 1295 e 1297 (14). Aí Turberville aparece prometendo a Carlos (irmão do rei da França, Filipe-o-Belo) fazê-lo conquistar toda a Inglaterra (15). Para tanto ele deveria preparar homens e navios, aguardando as notícias que the seriam enviadas acerca do melhor ponto da ilha para desembarcar. A descoberta da traição e a execução são cuidadosamente descritas pelo autor, que se delicia com o espetáculo do réu, sendo arrastado através da cidade até o cadafalso e injuriado ao longo do percurso inteiro, por seis "atormentadores" trajados como diabos. Mas - é o que mais nos interessa - encerra a obra com uma nota patriótica, afirmando ter Eduardo dado pouca importância às ameaças francesas, após guarnecer cautelosamente o mar com navios equipados por bravos guerreiros. Frustrado em seu intento, o inimigo dirigiu o ataque a Dover, sofrendo aí grandes baixas (alusão ao incêndio da cidade por piratas normandos em agosto de 1295).

As desinteligências franco-inglesas propiciadoras desse episódio haviam tido início por volta de 1290 , ao cabo de vários anos de tensão criada por questões pendentes do Tratado de París e, principalmente, pelo choque de soberania entre os dois monarcas, a propósito da administração da Gasconha e de suas incertas e turbulentas fronteiras. Nesse ambiente aberto à hostilidade, onde cada soberano e seus servidores estavam sempre à espreita das ocasiões favoráveis à expansão de seus poderes, era natural que pequenos incidentes assumissem desde logo proporções vultuosas. Assim os entreveros marítimos entre marinheiros ingleses, gascões, bretões e normandos entre 1289 e 1292 repercutiram amplamente nas cortes da Inglaterra e da França, azedando as relações entre ambas, trazendo, como consequência a ocupação progressiva da Gasconha por Carlos de Valois e o confisco dos feudos continentais de Eduardo por Filipe (16).

Em meio às querelas que se seguiram, até a paz de París de 1303, dois pontos chamaram a atenção do singleses para a política continental de seu rei: a aliança com Flandres e o seu casamento com Margarida, irmã de Filipe.

(14) - Publicado por I. S. T. Aspin, Anglo-Norman Political Songs, pp. 49-55.

(15) - Não sabemos que razões levaram o autor a citar Carlos em lugar de seu irmão Filipe. Poderia ter sido um engano com o nome do verdadeiro monarca, ou, então, o fez devido à destacada ação de Carlos na Gasconha entre 1294 e 1296. O mesmo erro, se foi, ocorre numa outra canção do período a qual trata da execução de um nobre escocês, Simão Fraser, capturado na batalha de Kirkencliff em 1306 (Wright, op. cit., p. 223).

(16) - Numa das pequenas canções transcritas na Crônica Métrica de Pedro Langtoft, o autor incentiva Eduardo a vingar-se do falso Filipe de França '(Wright, op. cit., p. 310). 
O acordo com Flandres (janeiro de 1297) fez parte do sistema de alianças que Eduardo procurou armar na região dos Paises Baixos e da Alemanha, visando criar aí uma diversão para o soberano francês, dificultando-lhe destarte a ação militar na Gasconha. Sem ser uma novidade, Ricardo I e João já haviam recorrido aos senhores daquelas partes contra Filipe Augusto, a manobra antecipava as futuras andanças de Eduardo III na Flandres, que marcariam o início da Guerra dos Cem Anos. Como ocorreria mais tarde, a ação de Eduardo I não passou desapercebida dos ingleses e um poeta a descreveu como uma gentileza do príncipe inglês em defesa do conde de Flandres, igualmente ameaçado pelo monarca francês (17).

Além disso, a famosa batalha de Courtrai, na qual os burgueses flamengos derrotaram o exército do conde de Artois foi celebrada especialmente num poema em inglês. Aquí é descrita a revolta do pessoal de Burges, liderado por um tecelão Pedro Conyng, contra os bailios e a guarnição francesa enviada para impor ordem na cidade ("matinas de Burges", 18 de maio de 1302). O envio da cavalaria francesa para lidar com os rebeldes resultou então no seu vergonhoso aniquilamento pelo exército popular flamengo:
"Alas! thou seli Fraunce, for the may thunche shome,
That ane fewe fullaris maketh ou so tome;
Sixti thousent on a day hue maden fot lome,
with eorl ant knyht.
Herof habbeth the Flemysshe suithe god game,
Ant suereth bi Seint Omer ant eke bi Seint Jame,
Yef hy ther more cometh, hit falleth huem to shame
with huem for te fyht." (18)

("Ah! tu França simplória, pode parecer-te uma vergonha, que uns poucos pisoeiros te façam tão mansa; num dia apenas fizeram sessenta mil chafurdar na lama, juntamente com conde e cavaleiro. Assim tiveram os flamengos um ótimo passatempo e juram por Santo Omer e Santiago que se vierem mais lutar com eles passarão pelo mesmo vexame.")

Quanto ao casamento de Margarida com Eduardo I, um dos resultados da mediação do papa Bonifácio na querela entre os dois soberanos, constitui o jubiloso remate numa Song on the Scottish Wars composta nessa época, muito embora a seu editor, Thomas Wright suspeitasse tratar-se de um acréscimo posterior ao corpo do poema (19). O casamento era, segun-

(17) - Song on the Scottish Woas, in Wright, op. cit., pp. 168-169.

(18) - Wright, op. cit., p. 194.

(19) - O casamento realizou-se em 4 de setembro de 1299, após a celebraçăo do acordo de Montreuil-sur-Mer em junho do mesmo ano. 
do o poeta, o penhor de uma paz mais completa entre os reinos, dissipando os amargos suspiros do peito dos súditos oprimidos pelas guerras. Numa distorção patriótica ele chega mesmo a afirmar que foi Filipe quem implorou uma trégua decorosa ao seu adversário insular. Aliás, ele também achava que seria o bom momento para os turbulentos vizinhos da Inglaterra, os escoceses, fazerem as pazes com Eduardo, o que só não ocorreu por catusa do orgulho e impiedade deles (20).

As divergências com os escoceses, iniciadas então, teriam vida quase tão longa quanto a querela com a França e, como esta, tinham entre suas causas imediatas a questão da soberania. Porém, ao contrário do envolvimento com a França, o papel de suserano coube, neste caso, ao rei da Inglaterra, enquanto o monarca escocês figurava como o vassalo recalcitrante. Eduardo havia recentemente afirmado seu domínio sobre Gales e aproveitou-se da vacância do trono escocês em 1290 para, como senhor suserano, pronunciar-se, em meio à disputa que se seguiu, a favor de João Baliol, em troca da homenagem feudal e do juramento de fidelidade (21).

Este, todavia, influenciado pelos nobres, tão logo se julgou firme no poder, deixou de cumprir as obrigações vassálicas, ecoando em termos insulares resistência semelhante à dos Plantagenetas em relação ao rei da França.

Tal portanto a origem do conflito anglo-escocês e da série de episódios sangrentos que se seguiram, ainda no reinado de Eduardo I. Para nós, particularmente, interessa notar que ele ligou-se às lutas continentais desde o princípio, graças às sucessivas alianças entre escoceses e franceses objetivando colocar os ingleses entre dois fogos. Foi justamente essa ligação o último dos fatores a atrair a atenção destes para a questão continental, contribuindo para exacerbar a crescente francofobia que alimentaria mais tarde a Guerra dos Cem Anos. O misto de inquietação e ódio em relação aos vizinhos setentrionais que aparece na literatura insular da época decorria mais dos quotidianos atritos fronteiriços (as frequentes incursões dos escoceses ao norte da Inglaterra), que propriamente da compreen-

(20) - Wright, op. cit., pp. 178-179. Na verdade Eduardo conseguiu astuciosamente deixar a Escócia fora do acordo de Montreuil, contrariando a vontade do papa, que pretendia uma pacificação geral.

(21) - O falecimento do rei da Escócia, Alexandre III, em 1286, deixou o governo do reino nas mãos de um conselho regencial que agia em nome de sua neta e única herdeira, Margarida (conhecida como the Maid of Norway) então com três anos de idade. Ela, porém nunca chegou a assumir a coroa, falecendo em 1290, quando se preparava para retornar da Noruega onde se encontrava. Seguiu-se uma acirrada disputa, com diversos pretendentes postulando seu direito ao trono. Os nobres escoceses, embora eceitando a arbitragem de Eduardo I recusavam-se a admití-lo como suserano, com direito de escolher a seu bel-prazer um dos candidatos. 
são e apoio à política hegemônica de Eduardo I. E justamente por isso ele era bem forte e com a mesma intensidade seria transferido para quaisquer aliados de seus inimigos naturais.

Os altos e baixos da história da aliança franco-escocesa não foram inteiramente captados pela poesia política; mas, conforme o rítmo típico dessas produções episódicas, aparecem em rápidas pinceladas alusivas a um ou outro acontecimento. Um poema latino, por exemplo, sobre a deposição de João Baliol, em 1290, refere-se à sua retirada para a Normandia e é irônico a respeito da esperança de auxílio francês por parte dos escoceses que, enquanto este não vinha, foram derrotados por três vezes (22). O autor de um outro trabalho a propósito da execução de sir Simão Fraser ocorrida após a batalha de Kirkencliff em 1306 também é cáustico quanto ao proveito do socorro a ser trazido por Carlos da França (23). E na Crônica Métrica de Pedro Langtoft, bastante próxima das canções políticas pelo conteúdo, rítmo da narração e sentimentos, franceses e escoceses são conjuntamente amaldiçoados, notando o autor a significativa coincidência das lutas nas duas frentes: ambos haviam se mancomunado para destruir os ingleses e repartir seu território entre eles, só não o conseguiram graças à pronta ação de Eduardo (24).

Esse tema da aliança franco-escocesa pontilha as produções poéticas do reinado de Eduardo III, já em plena guerra dos Cem Anos, revelandose por conseguinte uma das perenes preocupações da comunidade insular em relação às guerras com a Escócia. Seria evidentemente um exagero tomá-la como o único motivo do interesse dos ingleses pelos conflitos continentais de seus monarcas; todavia, não podemos deixar de notar a coincidência entre tal interesse e o início das lutas na fronteira setentrional sob Eduardo I. Enquanto os embaraços feudais dos Plantagenetas ficaram distanciados das fronteiras do reino, confinados às regióes além-Mancha, os ingleses puderam ignorá-los tranquilamente, reclamando apenas das exigências fiscais da Coroa para sustentar suas campanhas militares. Porém, desde que eclodiu a questão escocesa, logo entrelaçada com os negócios franceses, a cousa toda passou a ter um aspecto bem mais sério para o reino, pois agora a guerra, já endêmica ao norte, ameaçava chegar ao litoral meridional.

E havia razões para tais temores. Além do recrudescimento da pirataria bretã e normanda no golfo da Gasconha e nas águas do Canal, dos ataques a localidades costeiras da Inglaterra, não expusera o caso Turberville projetos mais grandiosos do soberano francês, visando punir o vassalo recalcitrante com a invasão de seu domínio insular?

(22) - Wright, op. cit., p. 180.

(23) - Cf. nota 15 .

(24) - Wright, op. cit., pp. 273-318. 
Em suma: a segurança; esta terá sido, em termos genéricos, o elemento que conseguiu sacudir a indiferença dos ingleses para com o intrincado problema feudal de seus monarcas no continente. A conjunção dos diversos incidentes bélicos no reinado de Eduardo I viera mostrar aos seus súditos que o inimigo tradicional dos Plantagenetas, desde os dias de Filipe Augusto, o era também de toda a nação inglesa, ameaçada agora por ele, direta ou indiretamente. E, numa curiosa simetria preparada pelo acaso histórico, conjunção semelhante de fatores vai reaparecer às vésperas do secular conflito do século XIV: a disputa pela sucessão na Escócia, os ataques dos escoceses e as ameaças de invasão da Inglaterra entre 1333 e 1339 .

Finalmente, à insegurança é preciso juntar ainda um outro ingrediente importante, não suficientemente enfatizado por nós, dados os limites que impusemos ao trabalho: a imagem cavaleiresca de Eduardo I, a qual ajudou a catalizar a atenção dos súditos para seus feitos d'armas, onde quer eles ocorressem. Não censuraram os trovadores à saciedade o espírito timorato e hesitante de setıs ancestrais João e Henrique III? Não se deliciaram com as proezas de Ricardo, o "coração de leão"? Posteriormente as mesmas qualidades vão reaparecer em Eduardo III, despertando similar entusiasmo entre os coevos, ecoando nos entusiásticos versos de um Lourenço Minot. Testemunho disso a notoridade que a revolta flamenga contra Filipa IV alcançou na Inglaterra, graças ao conde de Flandres: Assim suas empreitadas militares eram atentamente acompanhadas, arrancando acalorados aplausos do povo, fossem eles contra os franceses, contra os escoceses ou contra... os sarracenos!

Eduardo inflamara a imaginação popular com sua participação na cruzada em 1270, à qual pretendia voltar a dedicar-se tão logo os negócios do governo o permitissem. Contudo quis o destino que ele morresse sem poder realizar seu desejo. Para um contemporâneo entretanto esse destino tinha um nome: Filipe, o real impecilho para o retorno de Eduardo a Jerusalém:

"Kyng of fraunce, thou heuedest sunne,

That thou the counsail woldest fonde,

To latte the wille of kyng edward

To wende to the holy londe;

That oure kyng hede take on honde

Al engelond to yeme \& wysse,

To wenden in-to the holy londe,

To wynnen vs heuenriche blisse."

(25) - The death of Edward I. H. R. Robins, Historical Poems of the $X I V t h$ and $X V$ th centuries, p. 22. Esse poema foi composto originalmente em anglo-normando e logo traduzido para o inglês, com modificações em algumas estrofes. As duas versões foram publicadas por Wright, op. cit., pp. 241-250. 
(O rei da França, vós pecastes ao ter procurado conselho para embaraçar a vontade do rei Eduardo que pretendia ir à Terra Santa; que o nosso rei havia se encarregado de pregar e comandar a toda Inglaterra a ida à Terra Santa, para conseguir a bemaventurança eterna para nós.")

Concluindo: a leitura das canções políticas nos permite notar que o entusiasmo da nação inglesa pelas guerras de Eduardo III, tingido com as cores da xenofobia e de um incipiente sentimento nacional, não constituiu uma explosão tão súbita quanto possa parecer à primeira vista; mas, foi lentamente preparado desde o final do século XIII. Foi sob Eduardo I que surgiram razões suficientes fortes para interessar a comunidade do reino por um problema até então privativo da família Plantageneta, trazido por ela como uma onerosa herança de seu passado glorioso à frente de um império que cobria ambas as margens do canal da Mancha. 